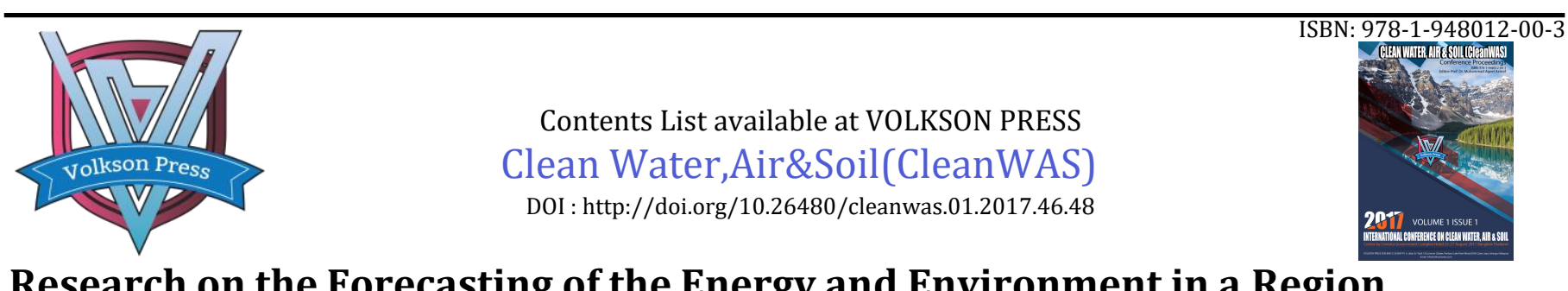

\title{
Research on the Forecasting of the Energy and Environment in a Region
}

\author{
Liu Shenyang *, Zhu Qian, Fu Yan, Luo Guangxu \\ Department of Aviation Four Stations, Air Force Logistics College, Xuzhou, 221000, China
}

This is an open access article distributed under the Creative Commons Attribution License, which permits unrestricted use, distribution, and reproduction in any medium, provided the original work is properly cited

\section{ARTICLE DETAILS}

\section{Article History:}

Received 02 october 2017

Accepted 06 october 2017

Available online 11 october 2017

Keywords:

Energy and environment, economic growth, ARIMA, ACF \&

PACF, forecasting method

\section{ABSTRACT}

Through making an analysis of the effect of energy and environment on economic growth in a region. The method of ARIMA and ACF \& PACF after difference is applied to forecast the fossil oil consumption and the sulfur dioxide emission in a region. The forecasting method provides a theoretical basis for environmental protection and economic growth and have the vital important guiding significance.

\section{Introduction}

Many scholars have made scientific researches on spare parts consumption [1]. Meanwhile the regional differences and coordination of overall economic growth performance in a region under constrained energy and environment are visible. The economic growth efficiency in a region is relatively low with a large space for improvement [2].

The regional energy consumption and sulfur dioxide emission are significantly different from the economic sustainable development in the area [3]. There was a significant gap between the coordination level of environmental protection and economic growth. Half of a region is belonged to uncoordinated or extremely uncoordinated regions. Taking effective measures to improve the utilization efficiency of energy and to promote environmental protection will be an important task for economic development in a region in the future.

However, through analyzing the scientific researches on regional energy consumption and sulfur dioxide emission, we could find that few papers have been published as of now regarding the method that is applied to forecast the fossil oil consumption and the sulfur dioxide emission in a region.

Based on the abstraction of above problems, the method of ARIMA and ACF \& PACF after difference after difference [4] is given to such kind of problems.

\section{Forecasting of the Energy and Environment}

The statistics of fossil oil consumption in a region from 2012 to 2016 is shown in Table 1 . The statistics of the sulfur dioxide emission in a region from 2012 to 2016 is shown in Table 2.

Table 1. The statistics of the fossil oil consumption in a region from 2012 to $2016\left(10^{9} \mathrm{~kg}\right)$

\begin{tabular}{l|l|l|l|l|l|l|l|l|l|l|l|l|l}
\hline Year & 1 & 2 & 3 & 4 & 5 & 6 & 7 & 8 & 9 & 10 & 11 & 12 & Total \\
\hline 2012 & 15 & 12 & 22 & 23 & 24 & 28 & 34 & 33 & 29 & 21 & 11 & 12 & 264 \\
\hline 2013 & 19 & 15 & 24 & 26 & 26 & 31 & 37 & 39 & 30 & 24 & 14 & 18 & 301 \\
\hline 2014 & 17 & 16 & 27 & 28 & 27 & 33 & 40 & 39 & 33 & 25 & 17 & 16 & 318 \\
\hline 2015 & 22 & 19 & 33 & 33 & 30 & 37 & 44 & 40 & 35 & 27 & 18 & 19 & 357 \\
\hline 2016 & 26 & 21 & 36 & 35 & 33 & 39 & 46 & 45 & 36 & 30 & 22 & 23 & 392 \\
\hline
\end{tabular}

Table 2. The statistics of the sulfur dioxide emission in a region from 2012 to $2016\left(10^{8} \mathrm{~kg}\right)$

\begin{tabular}{l|l|l|l|l|l|l|l|l|l|l|l|l|l}
\hline $\begin{array}{l}\text { Ye } \\
\text { ar }\end{array}$ & 1 & 2 & 3 & 4 & 5 & 6 & 7 & 8 & 9 & $\begin{array}{l}1 \\
0\end{array}$ & $\begin{array}{l}1 \\
1\end{array}$ & $\begin{array}{l}1 \\
2\end{array}$ & $\begin{array}{l}\text { To } \\
\text { tal }\end{array}$ \\
\hline 20 & 1. & 1. & 1. & 2. & 2. & 3. & 3. & 3. & 3. & 2. & 2. & 1. & 30. \\
12 & 6 & 7 & 9 & 2 & 5 & 1 & 6 & 9 & 4 & 9 & 1 & 7 & 8 \\
\hline 20 & 1. & 2. & 2. & 2. & 2. & 3. & 4. & 4. & 3. & 3. & 2. & 2. & 36. \\
13 & 8 & 0 & 4 & 8 & 9 & 5 & 1 & 3 & 8 & 6 & 8 & 1 & 1 \\
\hline 20 & 1. & 1. & 2. & 2. & 2. & 3. & 3. & 4. & 3. & 3. & 2. & 2. & 34. \\
14 & 8 & 6 & 2 & 5 & 7 & 4 & 8 & 2 & 7 & 1 & 5 & 7 & 2 \\
\hline 20 & 2. & 1. & 2. & 2. & 2. & 3. & 4. & 4. & 3. & 4. & 2. & 2. & 37. \\
15 & 0 & 9 & 3 & 7 & 9 & 6 & 5 & 1 & 8 & 3 & 5 & 9 & 5 \\
\hline 20 & 2. & 2. & 2. & 2. & 3. & 3. & 4. & 4. & 3. & 3. & 2. & 3. & 39. \\
16 & 5 & 1 & 9 & 7 & 1 & 7 & 9 & 4 & 8 & 2 & 8 & 3 & 4 \\
\hline
\end{tabular}

According to Table 1, the scheduling of original fossil oil consumption in a region from 2012 to 2016 is shown in Figure 1.

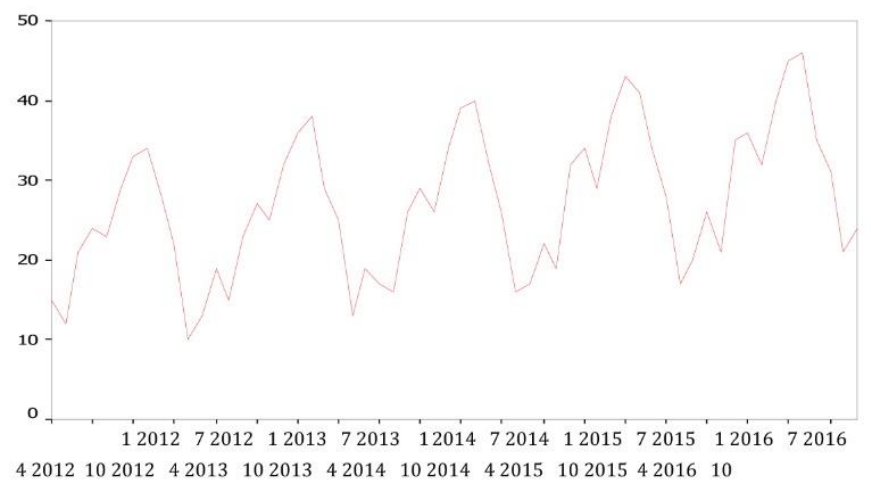

Figure 1. The scheduling of original fossil oil consumption in a region from 2012 to 2016

At first, the difference is applied for the data of twelve months. Based on this, the one step difference is put in practice [5]. The scheduling of consumption data of fossil oil after difference is shown in Figure 2. It can be found that the scheduling of consumption data of fossil oil after difference is stochastic and stable. 


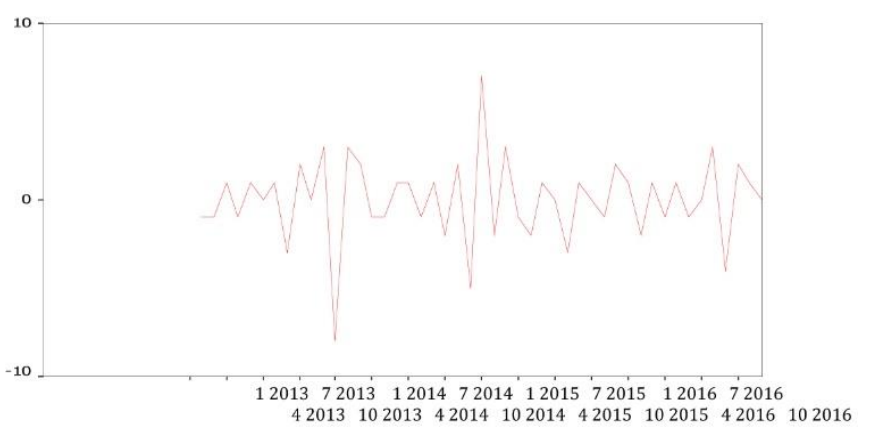

Figure 2. The scheduling of consumption data of fossil oil after difference

The figure of ACF after difference is shown in Figure 3, and the figure of PACF after difference is shown in Figure 4. It can be found that the scheduling of consumption data of fossil oil after difference is very stable from the figure of ACF and the figure of PACF.

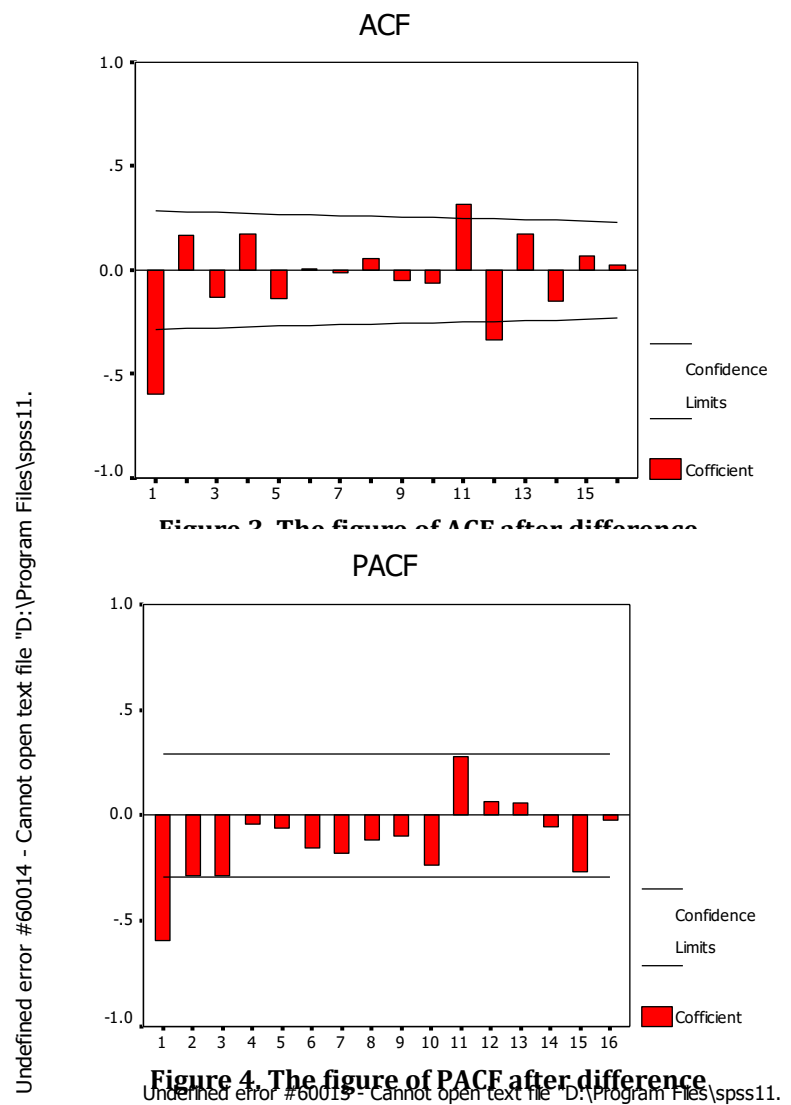

Secondly, according to the characters of the ACF after difference and PACF after difference, many models could be selected. Then judge the best model.

Six styles of models established are :

$$
\begin{aligned}
& (1,1,1) \times(1,1,1)_{12},(1,1,1) \times(0,1,1)_{12},(0,1,1) \times(1,1,1)_{12}, \\
& (0,1,1) \times(0,1,1)_{12},(0,1,1) \times(1,1,0)_{12},(1,1,0) \times(0,1,1)_{12} .
\end{aligned}
$$

The value of AIC and BIC of different models is shown in Table 3.

Talbe 3. The values of AIC and BIC of different model

\begin{tabular}{l|l|l|l|l|l|l}
\hline & 1 & 2 & 3 & 4 & 5 & 6 \\
\hline AIC & 181.2 & 180.7 & 179.6 & 177.5 & 179.1 & 192.0 \\
\hline BIC & 188.6 & 186.4 & 185.1 & 181.2 & 182.8 & 195.7 \\
\hline
\end{tabular}

From Table 3, it is obvious that the values of AIC and BIC of the fourth models is the smallest.

According to the principle that the values of AIC and BIC of the model is smallest. So the model of ARIMA $(0,1,1) \times(0,1,1)_{12}$ should be selected.
Thirdly, the least-squares regression method is applied to estimate the parameter. Estimate value of parameter and $t$-check value is shown in Table 4.

Table 4. Estimate values of parameters and t-check values

\begin{tabular}{l|l|l|l|l|l}
\hline Parameter & $\begin{array}{l}\text { Estimate } \\
\text { value }\end{array}$ & $\begin{array}{l}t \\
\text { check }\end{array}$ & Parameter & $\begin{array}{l}\text { Estimate } \\
\text { value }\end{array}$ & $\begin{array}{l}t \\
\text { check }\end{array}$ \\
\hline$\hat{\theta}$ & 0.975 & 2.111 & $\hat{\Theta}$ & 0.47 & 2.60 \\
\hline
\end{tabular}

All of the estimate values are remarkable, so the expression of the model is

$$
x_{t}=x_{t-1}+x_{t-12}-x_{t-13}+\varepsilon_{t}-0.975 \varepsilon_{t-1}-0.47 \varepsilon_{t-12}+0.45 \varepsilon_{t-13}
$$

The estimate value of the variance is $\sigma_{\varepsilon}^{2}=2.07$.

The ACF of difference sequence is shown in Figure 5, and the PACF of difference sequence is shown in Figure 6. It can be found that the model selected is very suitable.
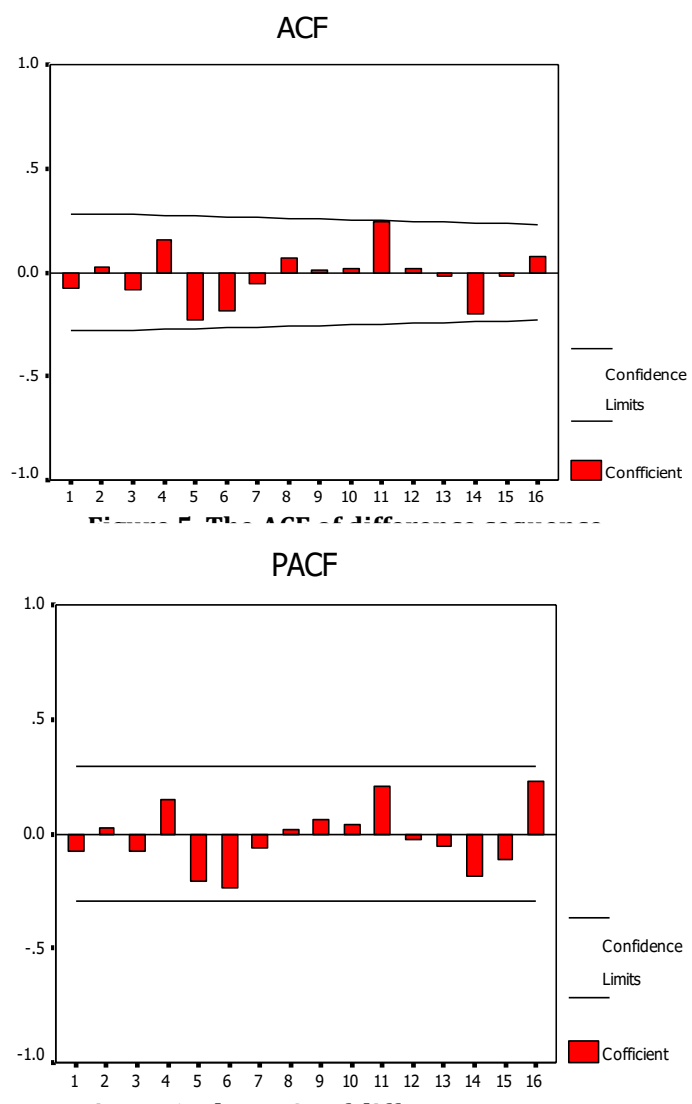

Figure 6. The PACF of difference sequence
Undefined error \#60013 - Cannot open text file "D: Program Files $\mid$ spss11.

The sequence of original data $\&$ simulate value $\&$ forecast value is shown in Figure 7. It is obvious that the effect of simulating and forecasting is good.

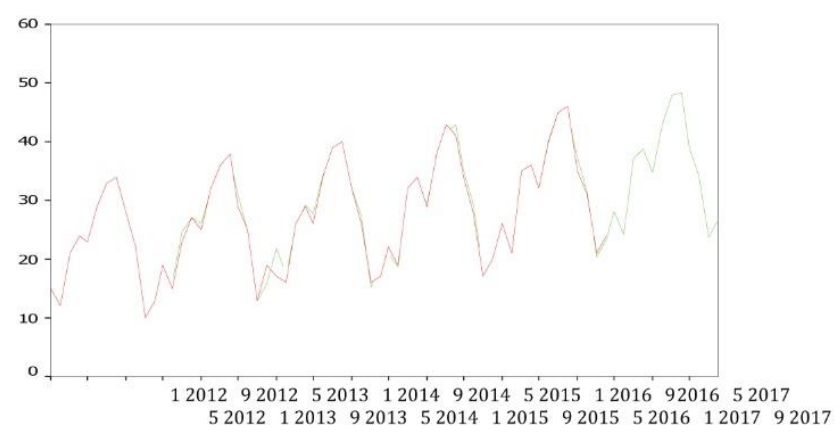

Figure 7. The sequence of original data $\&$ simulate value $\&$ forecast value

The forecasting values of fossil oil consumption in a region in 2017 is 
shown in Table 5.

Table 5. The forecasting values of fossil oil consumption in a region in $2017\left(10^{9} \mathrm{~kg}\right)$

\begin{tabular}{l|l|l|l|l|l|l|l|l|l|l|l|l|l}
\hline $\begin{array}{l}\text { Mo } \\
\text { nth }\end{array}$ & 1 & 2 & 3 & 4 & 5 & 6 & 7 & 8 & 9 & $\begin{array}{l}1 \\
0\end{array}$ & $\begin{array}{l}1 \\
2\end{array}$ & $\begin{array}{l}\text { Tot } \\
\text { al }\end{array}$ \\
\hline $\begin{array}{l}\text { Val } \\
\text { ue }\end{array}$ & 2 & 2 & 3 & 3 & 3 & 4 & 4 & 4 & 3 & 3 & 2 & 2 & 407 \\
\hline
\end{tabular}

According to Table 2, applying the method of ARIMA and ACF \& PACF after difference above, the values of sulfur dioxide emission in a region in 2017 could also be forecasted. The forecasting values of sulfur dioxide emission in a region in 2017 is shown in Table 6.

Table 6. The forecasting values of sulfur dioxide emission in a region in $2017\left(10^{8} \mathrm{~kg}\right)$

\begin{tabular}{l|l|l|l|l|l|l|l|l|l|l|l|l|l}
\hline Month & 1 & 2 & 3 & 4 & 5 & 6 & 7 & 8 & 9 & 10 & 11 & 12 & Total \\
\hline Value & 2.7 & 2.3 & 3.2 & 2.8 & 3.5 & 3.9 & 5.2 & 4.6 & 4.0 & 3.5 & 3.1 & 3.3 & 42.1 \\
\hline
\end{tabular}

The model of ARIMA and ACF \& PACF after difference has been applied in forecasting of the energy and environment in a region. It could be used to solve complicated, stochastic, unstable, periodic sequence. The precision of the model of ARIMA is higher than other time sequence models.

From Table 5 and Table 6 , it is obvious that the values of fossil oil consumption and sulfur dioxide emission are very big. It shows that the acid rain in the region is grievous. The people in the region must take some measures to solve the problem.

\section{CONCLUSION}

This paper applies the method of ARIMA and ACF \& PACF after difference to forecast the fossil oil consumption and the sulfur dioxide emission in a region, through making an analysis of the effect of energy and environment on economic growth in a region. The method could also be used in other regions. In oder to protect the environment and economic growth, people must take actions immediately.

\section{ACKNOWLEDGMENT}

This work is supported by the National Natural Science Fund of China (No.71401173)

\section{References}

[1] FARRELL M J. The Measurement of Productivity Efficiency [J]. Journal of the Royal Statistical Society, 2007, 120: 253-282.

[2] CHARNES A COOPER W W RHODES E. Measuring the efficiency of decision making units [J]. European Journal of Operational Research, 2008, 2: $429-444$

[3] TONE K. A Slacks - based measure of efficiency in data envelopment analysis [J]. European Journal of Operational Research, 2011, 30: 498-509. Naim T. Unlu. An Assessment of Demand Forecasting Methods for Weapon System Items[R]. ADA401563, 2001.

[4] Corchado J M, Brian L. A Hybrid Case-Based Model for Forecasting [J]. Applied Artificial Intelligence, 2001, 12(2):105-127.

\section{About the Authors}

Corresponding Author: Liu Shenyang (1988-), Male, Ph.D., Research Focus: Environment Engineeing and Equipment Management. Zhu Qian (1980-) , Male, Associate Professor.

Fu Yan (1973-) , Female, Lecturer.

Luo Guangxu (1988-) , Male, Lecturer. 